\title{
Cognitive-Behavioral Therapy (CBT) Is Applied in Post-Traumatic Stress Disorder (PTSD) of Chinese Shidu Parents Who Lost Their Only Child
}

\author{
Guilin Yu $\mathbb{D},{ }^{1}$ Hongfeng Liu, ${ }^{1,2}$ Chiang-Hanisko Lenny, ${ }^{3}$ Daijun Chen, ${ }^{1}$ Yin Yu, \\ and Chanyuan Sun ${ }^{1}$ \\ ${ }^{1}$ Hubei Province Key Laboratory of Occupational Hazard Identification and Control, \\ Wuhan University of Science and Technology, Wuhan, China \\ ${ }^{2}$ Suizhou Vocational and Technical College, Suizhou 441300, China \\ ${ }^{3}$ Christine E. Lynn College of Nursing, Florida Atlantic University, Boca Raton, FL 33431, USA
}

Correspondence should be addressed to Guilin Yu; yuguilin46@163.com

Received 20 January 2022; Revised 7 February 2022; Accepted 10 February 2022; Published 8 March 2022

Academic Editor: Thippa Reddy G

Copyright $\odot 2022$ Guilin Yu et al. This is an open access article distributed under the Creative Commons Attribution License, which permits unrestricted use, distribution, and reproduction in any medium, provided the original work is properly cited.

Objective. The objective is to help Chinese Shidu parents who have lost their only child to relieve post-traumatic stress disorder. Methods. A qualitative phenomenology study using the hermeneutical phenomenological method was employed in a major metropolitan city in China. Participants were 46 parents who had lost their only child and suffered from post-traumatic stress disorder. Three major themes are: (1) to conduct semistructured in-depth interviews with 46 Shidu parents; (2) to develop and implement a psychological intervention program combining with group intervention and individual counseling based on cognitive-behavioral therapy; (3) to assess the effect of psychological intervention through PTSD Checklist for DSM-5 (PCL-5). Results. Those Shidu parents who lost their only child got great relief from PTSD. The Shidu parents got great relief and changed a lot after the intervention. They became active to participate in group counseling and willing to help others because they experienced the value and fun in the process. They rebuilt their attachment and looked forward to their future life. Conclusion. Cognitive-behavioral therapy can alleviate and even cure post-traumatic stress disorder in Shidu parents who have lost their only child.

\section{Introduction}

The Shidu parents refer to the parents who have lost their only child. The death of the only child is a disaster for any one-child family. Since then, those who lost their only child had no spiritual sustenance, lost their life goals and pursuits. In the first few months, years, or even decades, they felt intense painful experiences and extreme behavioral reactions. As a result, they became depressed, autistic, sensitive, and vulnerable, and even retaliated against themselves or society because of their irrational cognition [1]. According to the research done by Liu [2] and other researchers, the PTSD rate of Shidu parents ranged from $69.5 \%$ to $80 \%$, and they generally avoided society.
The main symptoms of post-traumatic stress disorder (PTSD) [3] include repeated flashbacks of painful experiences and painful memories, avoidance of people and things related to the loss of original injury, increased alertness, and borderline paranoid personality. Shidu parents with PTSD cannot extricate themselves from grief, guilt, anger, and struggle all day long, which eventually pose a serious threat and heavy burden to themselves and society. A review of literature in Chinese and foreign languages in recent years reveals that there have been many crossregional studies on PTSD with large samples and large data, focusing on the correlation of symptoms, factors affecting the quality of life, and the moderating effect of social support, etc., but there are very few studies on psychological intervention. The 
researchers collected through the early stage of the data and found that cognitive-behavioral therapy was the standard therapy for post-traumatic stress disorder. [4] Cognitivebehavioral therapy (CBT) is a structured, short-term, cognitive-oriented psychotherapy developed by A. T. Beck in the 1960s. It is mainly aimed at psychological disorders such as depression, anxiety, post-traumatic stress disorder, and psychological problems caused by unreasonable cognition. A. T. Beck once said that maladaptive behaviors and emotions were both from maladaptive cognition. Cognitivebehavioral therapy can change the maladaptive emotions and behaviors of Shidu patients by changing their wrong cognition of themselves, people, or things and finally achieve the purpose of curing post-traumatic stress disorder. Considering the particularity of Shidu parents, this study adopts a qualitative research method and uses cognitivebehavioral therapy to conduct a psychological intervention for post-traumatic stress disorder of those Shidu parents, so as to provide the scientific basis for the government and social organizations to carry out relevant psychological work.

\section{Experimental Details}

2.1. Object. This study was carried out with the support of a community health and family planning department, community grid members, social volunteers, and psychological experts in Wuhan. In the family activity center of a community in Wuhan, we held health lectures and reading meetings every Thursday morning to build a close relationship with the Shidu parents. We finally identified 46 participants suffering from post-traumatic stress disorder (PTSD) from 190 Shidu parents who lost their only child through group discussion and questionnaire survey (Table 1). The participants were in a good mental state and have good expression ability, and they all signed informed consent.

\section{Methods}

3.1. PTSD Checklist for DSM-5 (PCL-5) [5]. By using the scale to conduct a questionnaire survey, 33 points were used as the positive demarcation score to screen out the patients with post-traumatic stress disorder; the scale was used to evaluate the effect of psychological intervention in the process of psychological intervention. The PTSD score decreased, indicating that the intervention was effective. When the PTSD score decreased to less than 33 points, the patients with posttraumatic stress disorder were cured.

\subsection{Data Collection and Analysis-Interpretative} Phenomenological Analysis. Upon receiving the University IRB approval, the data were collected by trained researchers through semistructured in-depth interviews. The data collected were tape-recorded with the participants' consent, and notes were taken to enable the precision of statements. Each face-to-face, tape-recorded interview lasted 2 to 3 hours. And the information was obtained with PTSD Checklist for DSM-5 (PCL-5) as the topic.
3.3. Implementation of Cognitive-Behavioral Therapy. A psychological intervention program combining individual counseling and group intervention based on cognitivebehavioral therapy was developed and gradually implemented. During the intervention period, PTSD scores were evaluated every 3 months, and the program was modified according to the evaluation results before implementation. The frequency of treatment was once a week in the first month, followed by once every two weeks for a total period of a year.

3.4. Case Counseling-Cognitive-Behavioral Therapy (CBT) Helps Shidu Parents to Accept Themselves. First, cognitivebehavioral therapy was applied to help Shidu parents to accept reality and to restore the self. Through professional psychological counseling, Shidu parents were encouraged, and they clearly realized that the child has passed away. Instead of denying reality, they should strive to live a strong and valuable life. The application of cognitive-behavioral therapy helped Shidu parents get rid of the pain of losing their only child and pay more attention to the personal value realization.

Second, cognitive-behavioral therapy (CBT) was applied to help Shidu parents to correct irrational cognition and rebuild the cognitive structure. (1) Explain the significance and the implementation steps of cognitive-behavioral therapy. (2) Find out the irrational cognition of the Shidu parents by talking with them. (3) Guide Shidu parents to discover their irrational cognition, help them to realize that irrational cognition will lead to emotional and behavioral obstacles, which will eventually affect their normal life, inspiring the determination to correct irrational cognition. (4) By using the techniques of arguing with irrational cognition, imagining, and relaxation training, we help Shidu parents to correct their irrational cognition, establish correct and rational cognition, and improve their cognitive, emotional, and behavioral selfmanagement abilities. (5) Summarize the examples of good changes in Shidu parents' lives after the intervention, and we further strengthen the significance of establishing rational cognition.

Third, the application of cognitive-behavioral therapy helped Shidu parents learn to self-heal: relax the body, release, and transfer bad emotions. Shidu parents were guided to master relaxation training methods such as breathing, muscles, and imagination so that they could adjust themselves at any time and control their own physiological and psychological changes independently.

3.5. Group Intervention-Cognitive-Behavioral Therapy (CBT) to Help the Shidu Parents Rebuild Their Attachment Relationship. First, Shidu parents often identify with other parents who lost their only child as Tong Ming Ren, which means "those who share the same destiny" [6]. Shidu parents believe that only in groups they can better face the pressures and challenges of life. In the group, Shidu parents can get psychological comfort, support each other, and stay together for warmth [7]. The researchers encouraged Shidu parents to 
TABLE 1: Data of research subjects.

\begin{tabular}{|c|c|c|c|}
\hline Characteristics & & $\mathrm{N}$ & Percentage (\%) \\
\hline \multicolumn{4}{|l|}{ Gender } \\
\hline & Male & 21 & 45.7 \\
\hline & Female & 25 & 54.3 \\
\hline \multicolumn{4}{|l|}{ Age } \\
\hline & $50-60$ & 12 & 26.1 \\
\hline & $60-70$ & 19 & 41.3 \\
\hline & $\geq 70$ & 15 & 32.6 \\
\hline \multicolumn{4}{|l|}{ Marital status } \\
\hline & Couple & 29 & 63.04 \\
\hline & Single & 17 & 36.96 \\
\hline \multicolumn{4}{|l|}{ Education } \\
\hline & Middle school or under & 26 & 56.5 \\
\hline & Senior high school & 11 & 23.9 \\
\hline & Undergraduate or above & 9 & 19.6 \\
\hline \multicolumn{4}{|c|}{ Annual household income (yuan/month) } \\
\hline & $\leq 2000$ & 25 & 54.3 \\
\hline & $2000-5000$ & 14 & 30.4 \\
\hline & $\geq 5000$ & 7 & 15.3 \\
\hline \multicolumn{4}{|l|}{ Residence status } \\
\hline & Solitude & 15 & 32.6 \\
\hline & Live with family/relatives & 31 & 67.4 \\
\hline \multicolumn{4}{|l|}{ Self-care ability } \\
\hline & Fully care & 30 & 65.2 \\
\hline & Barely provide for oneself & 15 & 32.6 \\
\hline & Cannot provide for oneself & 1 & 2.2 \\
\hline \multicolumn{4}{|c|}{ Time since the child's death } \\
\hline & 6 months $\sim 1$ year & 2 & 4.3 \\
\hline & 1 year 5 years & 18 & 39.1 \\
\hline & 5 yesrs $\sim$ & 26 & 56.6 \\
\hline \multicolumn{4}{|l|}{ Cause of death } \\
\hline & Accident & 26 & 56.5 \\
\hline & Disease & 19 & 41.3 \\
\hline & Missing & 1 & 2.2 \\
\hline
\end{tabular}

get familiar with each other and participate in group activities as soon as possible through health lectures, readings, and games.

Second, spring and autumn outings, farmhouse entertainment, festival celebrations, and other activities were organized to help those Shidu parents gradually get out of the group and contact the society, enhance their interpersonal communication skills, feel the joy of life, and thus overcome their social avoidance behaviors and mentality.

Third, the Shidu parents are guided to participate in the activities of love, such as accompanying, playing with the children in the orphanage, holding Thanksgiving education lectures in the young labor camps, establishing "One Helps One" psychological intervention to link with university students, and motivate Shidu parents' emotion as fathers and mothers as well as the responsibility to society. By feeling love and being loved at the same time, they could repair the heart ruins and rebuild benign self.

Fourth, expert lectures on the meaning of life should be carried out to encourage those Shidu parents to discuss their ideal of life and gradually guide them to transfer their attachment to other more positive and lasting aspects, such as their own health, interests, and hobbies, and helping others.

Reassessment of PTSD scores is carried out.

\section{Results}

After psychological intervention through cognitive-behavioral therapy, the psychological state of the Shidu parents has undergone a great change.

Shidu parents accept the fact that their child has left and keep connected with their child in a positive way so that their grief can be greatly relieved.

We applied cognitive-behavioral therapy for case studies, such as subject P1 kept saying, "My son, I miss him, I do not know what to do, I'm so broken. .." Only by helping P1 unload her psychological burden could she start a new life. The researchers performed the true story of the child's death in the form of "psychodrama", allowing the Shidu parents to naturally vent their emotions, role-playing their children, and guiding them to say the words they have been hiding in their mind, including guilt and missing, to help them formally bid farewell to their children. Finally, subject P1 went to the child's grave to say goodbye and said to the child, "Son, you go......, you go to study, you go to serve the country, you go busy with your own things, I will take care of myself, I also want to live my own life". Then, she burned all the child's relics. Subject P1 said: "Since I said goodbye to my baby, I have felt a lot lighter and I do not have to be sad all the 
time. Now I sing when I have free time. I love singing." "I still miss my son. When I miss him, I sing songs of longing until tears run out of my eyes. After singing, I feel very happy."

Shidu parents should establish correct and positive cognitive concepts, learn to self-heal, be able to control their own emotions and behaviors, and accept the present self-more.

Irrational cognition leads to negative emotions and destructive behaviors, which will become a major source of stress over time. For example, subject P4 said before: "The death of children is caused by myself, and I am a disaster, so I should live an unhappy life". Subject P5 said: "I always feel sick....."; subject P16 thought: "People nowadays are snobbish and deliberately look down on me. ....". Through cognitive-behavioral therapy, the Shidu parents could correct the irrational cognition of stress and reconstruct the positive and adaptive cognitive structure. Under the guidance of correct cognition, they were more positive and optimistic in mood, and their behaviors were more conducive to their own development. In the process of psychological intervention, self-healing methods were taught to the research subjects to help those Shidu parents control bad emotions and relax their body and mind. After the intervention, subject P4 said: "I rarely blame myself, even if occasionally remorse, I will quickly transfer attention. People's life may be long or short, but only a few decades of time. My poor son left before me, but I also must go one day. There is really nothing to blame and care about. I want to live a good life, which is what my son wants me to do." Subject P5 said: "When I'm not feeling well, I just take a deep breath or go outside to relax and feel comfortable." Subject P16 mentioned: "Don't care too much about other people's eyes, my husband is good to me on the line, I've been working hard for most of my life, and I will love myself for the rest of my life. I will praise and hug myself every day."

Participate actively in group activities, enjoy helping others, and experience value and fun from these activities.

By the early group intervention of cognitive behavior therapy, the relationship between the researchers and participants became increasingly close. The participants have also mentioned that participating in the outdoor activities made them relaxed and joyful and helping others manifested their own value, and Shidu parents were then no longer obsessed with the pain of losing their only child and were willing to put the limited energy into pleasure and value. Subject P18 said: "I'm older and I've got rheumatoid arthritis, but I feel a lot better and my pain get relieved when I come out and gather with people"; subject P22 said: "People of my generation have suffered hardships and are dedicated. We are willing to offer help to those in need." Subject P25 mentioned: "I am a member of the Communist Party of China, I was eager to work overtime in the unit in the past time. Now that I am old, I need to spend more time taking care of myself, but if I am needed, I am willing to help others as long as my health is available." Subject P31 established a connection with a student in a university in Wuhan who was mentally reduced and physically limited after brain tumor surgery. Subject P31 always encouraged the students and their parents. Subject P31 said: "This child, I like at first sight, $\mathrm{He}$ is about the same age as my son, but he is also very poor, I want to encourage him, to help him fight the disease."

Reconstruct attachment relationship [8] and be full of longing for future life.

The Shidu parents have the right connection with their children in the early stage, and they can face themselves and others positively and experience the fun and value from these things. After that, they hope to establish a more lasting and positive attachment relationship. Through expert lectures and group intervention discussions, the participants can find their personal meaning of life. Subject P35 said: "I had the idea of writing a book when I was young, and now I have the time to do it." Subject P37 said: "I love dancing, I would like to take you to the square dance, I hope to have the opportunity to participate in the square dance competition." Subject P39 said: "I want to travel while I am still healthy, I want to visit the motherland's beautiful mountains and rivers, visit the good scenery at home and abroad." Subject P40: "My father is 100 years old, my aunt is 97 years old, and I'm 71 years old now, I'm trying to live to be 108 years old." Subject P43 said: "I like playing online games, watching TV, traveling and shopping. There are many interesting things waiting for me." Subject P46 said: "I will keep doing Tai chi every day, waiting for my grandson to get married, and then I will have great grandchildren."

Post-traumatic Stress Disorder was alleviated in the Shidu parents (Table 2).

With the deepening intervention of cognitive-behavioral therapy, the scores of post-traumatic stress disorder of Shidu parents who lost their only child gradually decreased, and some of them had dropped to less than 33 points, indicating that the post-traumatic stress disorder of the Shidu parents had been cured. There are still two Shidu parents whose scores were over 33 points, but compared to the original score, the decline is obvious.

\section{Discussion}

5.1. Necessity and Importance of Psychological Intervention for the Psychological Trauma of the Shidu Parents. This study found that although the loss of the original trauma occurred for several years or more, some of Shidu parents still suffered from PTSD. In this way, these Shidu parents should be carried out psychological intervention after the loss of their only child. However, all participants reported no prior psychological intervention from any organization or individual, and all of the participants reported that they would get over their grief sooner and faster if someone had been involved with them, especially in the immediate aftermath of their child's death. At present, the psychological intervention on the psychological trauma of the Shidu parents has not been caused widespread attention, and there is a big flaw and insufficiency. It needs to call on the government, social organizations, and professionals in the psychological field to focus on the mental health of Shidu parents, using scientific and systematic psychological therapy providing early psychological intervention for the Shidu parents. These 
TABLE 2: PTSD scores of subjects before and after cognitive-behavioral therapy intervention (unit: points).

\begin{tabular}{|c|c|c|c|c|}
\hline Subjects & Initial scores & 1 year after the intervention & $t$ & $p$ \\
\hline PTSD scores & $43.11 \pm 13.42$ & $14.15 \pm 5.25$ & 13.783 & $0.000^{* *}$ \\
\hline Intrusive symptoms & $11.13 \pm 4.22$ & $4.15 \pm 1.83$ & 9.441 & $0.000^{* *}$ \\
\hline Withdrawal symptoms & $3.93 \pm 1.61$ & $1.89 \pm 1.45$ & 6.511 & $0.000^{* *}$ \\
\hline Cognition and negative emotion & $16 \pm 5.39$ & $3.15 \pm 2.37$ & 14.669 & $0.000^{* *}$ \\
\hline Increased alertness & $12.04 \pm 3.93$ & $4.96 \pm 2.98$ & 11.010 & $0.000^{* *}$ \\
\hline
\end{tabular}

${ }^{*} p<0.05,{ }^{* *} p<0.01$.

measures can help Shidu parents to relieve the pain of original injury, early resumption of ourselves, and return to society. The purpose of this study is to explore the scientific and effective psychological intervention methods for posttraumatic stress disorder of the Shidu parents who have lost their only child.

5.2. Cognitive-Behavioral Therapy can Alleviate Post-traumatic Stress Disorder in Shidu Parents Who Have Lost Their Only Child. After 1 year of psychological intervention with cognitive-behavioral therapy, all of the participants have accepted the reality, rebuilt their attachment relationships, and actively faced life, indicating that the posttraumatic stress disorder of the Shidu parents has been significantly relieved or even cured in some cases. Two of them still had obvious symptoms of post-traumatic stress disorder. The possible factors were as follows: first, both of them were female, with relatively sensitive and fragile character, especially subject P27 suffered from an anxiety disorder when she was young. Second, they are very close to their children and regard them as the only ideal in their life. Third, they place high hopes on their children's path to success, but their children die shortly after becoming successful, and it is a huge blow. Although they did not get rid of PTSD, their previous major symptoms such as depression and withdrawal were significantly alleviated. Currently, only mild guilt and insomnia symptoms remain, which should be alleviated with further intervention. Most studies confirmed that the cognitive-behavioral therapy intervention on depression [9], sorrow [10], anxiety [11], psychological problems such as post-traumatic stress disorder $[12,13]$ was effective. Moreover, it has many advantages, such as low requirements on therapists, convenient and easy implementation, and extensive coverage, so the cognitive-behavioral therapy on Shidu parents with post-traumatic stress disorder has extensive application prospects in China.

\subsection{Limitations and Prospects of Cognitive-Behavioral} Therapy in the Process of Psychological Intervention. Cognitive-behavioral therapy has developed into a very systematic and mature therapy, which can directly solve existing psychological problems and correct dysfunctional thoughts and behaviors, and has been successfully applied to completely different psychiatric patients and populations. [14]. The participants of this study were persuaded to voluntarily accept psychological intervention, and their psychological status was relatively stable, and their mentality was more positive than that of the ordinary Shidu parents. The research process of cognitive-behavioral therapy for the post-traumatic stress disorder of the Shidu parents was very smooth, and the post-traumatic stress disorder of the participants was relieved to a certain extent. However, we should not assume that this type of psychotherapy is appropriate for all Shidu parents with PTSD. In China, there are many more severe cases of post-traumatic stress disorder among Shidu parents, and they cannot get over the grief of losing their only child, lose hope for life, and refuse all help [8]. It is difficult for researchers to intervene in the Shidu parents with such strong resistance to psychotherapy. There are also those Shidu parents with extreme thoughts and paranoid terror. Because they complain about injustice, hate others, or even revenge against society, they already have serious personality disorders. In this case, researchers could try a combination of CBT therapy, drugs, and electric shocks $[15,16]$. In conclusion, CBT therapy has many advantages, such as low requirements for therapists, convenient implementation, and wide range of involvement. Therefore, CBT therapy has a wide application prospect in the intervention of post-traumatic stress disorder in parents who lost their only child in China.

\section{Conclusion}

To sum up, cognitive-behavioral therapy can alleviate the post-traumatic stress disorder of Shidu parents, and the combination of group intervention and individual counseling is very practical and effective, which is worth popularizing.

\section{Data Availability}

The datasets used and/or analyzed during the current study are available from the corresponding author on reasonable request.

\section{Conflicts of Interest}

The authors declare that they have no conflicts of interest.

\section{Acknowledgments}

The authors thank all those who have helped in the course of writing this paper. This work was supported by the National Social Science Foundation of China (grant no. 17BSH119). 


\section{References}

[1] B. Liu, "Formation of borderline personality disorder in shidu patients and Transference focus therapy," Journal of Henan Institute of Education (Philosophy and Social Science Edition), vol. 39, no. 04, pp. 89-94, 2020.

[2] B. Liu, "Research on post-traumatic stress disorder and its rescue mechanism in shidu loss group," Journal of Xinyang Normal University (Natural Science Edition), vol. 40, no. 05, p. 2, 2020.

[3] Eli Buzohre, Y. Zhou, Y. Liang et al., "A profile analysis of post-traumatic stress disorder and depressive symptoms among Chinese Shidu parents," European Journal of Psychotraumatology, vol. 11, no. 1, p. 1766770, 2020.

[4] Z. Zhu, F. Li, G. Zhou et al., "Research progress on mental health and psychological support of families of the shidu parents," Chinese Journal of Health Psychology, vol. 27, no. 06, pp. 954-957, 2019.

[5] M. Deng, "New advances in clinical research of post-traumatic stress disorder (DSM-5 new standard)," Chinese Journal of Health Psychology, vol. 24, no. 05, pp. 641-650, 2016.

[6] Y. Zheng and T. R. Lawson, "Identity reconstruction as shiduers: narratives from Chinese older adults who lost their only child," International Journal of Social Welfare, vol. 24, no. 4, pp. 399-406, 2014.

[7] S. Fang, "Spiritual community and Double introversion: a Study on the Construction of self-organization of the Elderly who lost their only child in China -- Based on the Comparative Analysis of the self-organization of four elderly who lost their only child," Theory Monthly, no. 05, pp. 174-181, 2018.

[8] D. Zalaznik, M. Weiss, and J. D. Huppert, "Improvement in adult anxious and avoidant attachment during cognitive behavioral therapy for panic disorder," Psychotherapy Research, pp. 1-17, 2019.

[9] Z. Huang, Q. Han, Lu Yian et al., "Effects of cognitive behavioral therapy on insomnia and depression in patients with insomnia and depression," Nursing Research, vol. 35, no. 01, pp. 80-85, 2021.

[10] R. A. Bryant, L. Kenny, J. Amy et al., "Predictors of treatment response for cognitive behaviour therapy for prolonged grief disorder," European Journal of Psychotraumatology, vol. 8, no. sup6, 2019.

[11] C. Yuan, "Application of cognitive behavioral therapy in test anxiety intervention," Journal of Primary and Secondary School Mental Health Education, vol. 10, pp. 53-56, 2021.

[12] H. Martine and A. L. Mélissande, "Latent class analysis of post-traumatic stress symptoms and complex PTSD in child victims of sexual abuse and their response to Trauma-Focused Cognitive Behavioural Therapy," European Journal of Psychotraumatology, vol. 11, no. 1, 2020.

[13] S. Åkerblom, S. Perrin, M. Rivano Fischer, and M. McC. Lance, "Treatment outcomes in group-based cognitive behavioural therapy for chronic pain: an examination of PTSD symptoms," European Journal of Pain, vol. 24, no. 4, 2020.

[14] K. Lee Raby and M. Dozier, "Attachment across the lifespan: insights from adoptive families," Current Opinion in Psychology, vol. 25, pp. 81-85, 2019.

[15] H. Qi, S. Jufeng, and Ma Jun, "Cognitive behavioral therapy combined with repeated transcranial magnetic stimulation improves sleep and anxiety and depression in patients with stroke," Neural Injury and Functional Reconstruction, vol. 16, no. 11, pp. 669-671, 2021.
[16] H. Haixiao, L. Cuilv, and Z. Lijun, “Application of handwork combined with Network cognitive behavioral therapy in rehabilitation of patients with mental disorders and hypertension," Guangdong medical journal, vol. 41, no. 22, pp. 2343-2347, 2020. 